\title{
Allylmethylsulfide, a Sulfur Compound Derived from Garlic, Attenuates Isoproterenol-Induced Cardiac Hypertrophy in Rats
}

\author{
Soheb Anwar Mohammed, ${ }^{1}$ Bugga Paramesha, ${ }^{1}$ Yashwant Kumar, ${ }^{1}$ Ubaid Tariq, ${ }^{1}$ \\ Sudheer Kumar Arava $\mathbb{D}^{1},{ }^{2}$ and Sanjay Kumar Banerjee $\mathbb{D}^{1,3}$ \\ ${ }^{1}$ Non-Communicable Diseases Group, Translational Health Science and Technology Institute (THSTI), 121001, Faridabad, India \\ ${ }^{2}$ Department of Pathology, All India Institute of Medical Sciences, New Delhi 110029, India \\ ${ }^{3}$ Department of Biotechnology, National Institute of Pharmaceutical Education and Research (NIPER), Guwahati, \\ Assam 781101, India
}

Correspondence should be addressed to Sanjay Kumar Banerjee; skbanerjee@thsti.res.in

Received 30 January 2020; Accepted 25 March 2020; Published 12 June 2020

Academic Editor: Luciana Mosca

Copyright (c) 2020 Soheb Anwar Mohammed et al. This is an open access article distributed under the Creative Commons Attribution License, which permits unrestricted use, distribution, and reproduction in any medium, provided the original work is properly cited.

\begin{abstract}
Allylmethylsulfide (AMS) is a novel sulfur metabolite found in the garlic-fed serum of humans and animals. In the present study, we have observed that AMS is safe on chronic administration and has a potential antihypertrophic effect. Chronic administration of AMS for 30 days did not cause any significant differences in the body weight, electrocardiogram, food intake, serum biochemical parameters, and histopathology of vital organs. Single-dose pharmacokinetics of AMS suggests that AMS is rapidly metabolized into Allylmethylsulfoxide (AMSO) and Allylmethylsulfone $\left(\mathrm{AMSO}_{2}\right)$. To evaluate the efficacy of AMS, cardiac hypertrophy was induced by subcutaneous implantation of ALZET ${ }^{\circledR}$ osmotic minipump containing isoproterenol $(\sim 5 \mathrm{mg} / \mathrm{kg} / \mathrm{day})$, cotreated with AMS (25 and $50 \mathrm{mg} / \mathrm{kg} /$ day) and enalapril $(10 \mathrm{mg} / \mathrm{kg} /$ day) for 2 weeks. AMS and enalapril significantly reduced cardiac hypertrophy as studied by the heart weight to body weight ratio and mRNA expression of fetal genes (ANP and $\beta$-MHC). We have observed that TBARS, a parameter of lipid peroxidation, was reduced and the antioxidant enzymes (glutathione, catalase, and superoxide dismutase) were improved in the AMS and enalapril-cotreated hypertrophic hearts. The extracellular matrix (ECM) components such as matrix metalloproteinases (MMP2 and MMP9) were significantly upregulated in the diseased hearts; however, with the AMS and enalapril, it was preserved. Similarly, caspases 3, 7, and 9 were upregulated in hypertrophic hearts, and with the AMS and enalapril treatment, they were reduced. Further to corroborate this finding with in vitro data, we have checked the nuclear expression of caspase 3/7 in the H9c2 cells treated with isoproterenol and observed that AMS cotreatment reduced it significantly. Histopathological investigation of myocardium suggests AMS and enalapril treatment reduced fibrosis in hypertrophied hearts. Based on our experimental results, we conclude that AMS, an active metabolite of garlic, could reduce isoproterenol-induced cardiac hypertrophy by reducing oxidative stress, apoptosis, and stabilizing ECM components.
\end{abstract}

\section{Introduction}

Cardiovascular diseases (CVDs) contribute the highest among the noncommunicable disease's deaths globally; nearly 17.8 million deaths were reported due to CVDs alone in the year 2017 [1]. Cardiac hypertrophy $(\mathrm{CH})$ is a compensatory phase of the heart against various underlying pathophysiological stimuli. If untreated, $\mathrm{CH}$ progresses into the decompensatory phase, and which ultimately results in the irreversible heart failure. During this transition phase, an increase in myocardial mass, sarcomeric reorganization, expression of fetal genes, and remodeling of extracellular matrix take place [2].

The extracellular matrix (ECM) of the adult myocardium hosts both cardiomyocytes and interstitial cells in a complex three-dimensional orientation. ECM in addition to mechanical support also serves as a reservoir of growth factors to maintain basal physiology. During myocardial stress, homeostasis 
of the ECM is perturbed, resulting in systolic and diastolic dysfunctions due to compromised signal transduction [3]. In myocardial remodeling, a fine balance between synthesis and breakdown of ECM components is perturbed. Specifically, matrix metalloproteinase (MMP) activation was reported in various cardiovascular complications [4]. Cardiac fibrosis, an underlying pathophysiological stage in many cardiovascular complications, results due to abnormal ECM deposition [5]. Activation of MMPs and inhibition of tissue inhibitor of matrix metalloproteinases (TIMPs) favors ECM degradation and its accumulation in the myocardium [6].

Several attempts have been made to inhibit ECM remodeling by inhibiting MMPs in the diseased heart and thereby reduce heart failure [7]. But none of the matrix metalloproteinase inhibitors succeed as a drug for heart failure [8]. Therefore, researchers are more interested to explore natural compounds or nutraceutical agents to inhibit ECM remodeling and thus prevent or delay the disease progression. Evidence-based studies in the past have shown the pivotal role of gaseous signaling molecules such as hydrogen sulfide $\left(\mathrm{H}_{2} \mathrm{~S}\right)$ and sulfur dioxide in mitigating cardiovascular complications $[9,10]$. Hence, there is a pressing need to identify novel sulfur molecules to reverse the remodeling of cardiovascular complications. Among all the kinds of vegetables and fruits that are enriched with sulfur-rich compounds, garlic is more promising to show a cardioprotective effect.

Nutraceutical properties of the garlic against various complications are documented in ancient scriptures. Both prophylactic and therapeutic effects of garlic were promising in cardiometabolic complications [11] Despite having myriad beneficial effects of raw garlic, largely, people avoid it because of the gastric disturbing property of garlic due to the presence of allicin.

Earlier, we have reported the promising cardiometabolic properties of garlic [12-14]. During the LC-MS investigation of sulfur compounds in garlic-fed rat serum, we have identified Allylmethylsulfide (AMS) as one of the major garlicderived metabolites [15]. Similarly, in clinical studies, serum, breast milk, and urine samples also showed the presence of AMS [16, 17]. Pretreatment of AMS ameliorated X-rayinduced inflammation in mouse kidney [18]. It is reported that garlic intervention in various forms ultimately results in the formation of AMS in the physiological system. Therefore, it could be hypothesized that the beneficial effects of garlic such as lipid-lowering, antiatherosclerotic, antidiabetic, antihypertensive, antioxidant, and anticancer are attributed to its active metabolite AMS [19, 20].

Isoproterenol (isoprenaline) is a synthetic nonspecific beta-adrenergic receptor agonist. Sustained release of isoproterenol induces cardiac hypertrophy followed by myocardial remodeling and ultimately leading to heart failure [21]. Biochemical and pathophysiological perturbations due to isoproterenol are very similar to human disease settings and mimic anxiety- and stress-induced cardiac hypertrophy [22]. Hence, isoproterenol-induced cardiac hypertrophy in rodents is considered a suitable model to test the efficacy of novel molecules.

In our previous study, we have reported the antihypertrophic effect of AMS on cardio myoblast [15]. However, the in vivo effect of AMS in cardiac hypertrophy and molecular mechanism underlying the beneficial effect, if any, is not explored yet. Therefore, the present study was designed to find the effect of AMS on isoproterenol-induced cardiac hypertrophy and to explore its molecular mechanism mostly focusing on oxidative stress, apoptosis, and alteration of ECM components.

\section{Material and Methods}

2.1. Animals and Study Design. Male Sprague Dawley Rats of 200-250-gram weight were procured form the National Institute of Pharmaceutical Education and Research (Mohali, India). All animal studies were performed in accordance with the standard operating procedures of the Translational Health Science and Technology Institute (THSTI) and with Institutional Animal Ethical Committee (IAEC/THSTI/2015-4) approval, Faridabad. Animals were housed in a small animal facility of THSTI, maintained at a $22 \pm 2^{\circ} \mathrm{C}$ temperature, $50 \pm 15 \%$ relative humidity, and $12 \mathrm{hrs}$ of dark and light cycle.

2.1.1. Safety Study. Fifty-six animals were randomly divided into seven groups $(n=8)$ : Group 1 (control), Group 2 (corn oil/vehicle control), Group 3 (garlic $250 \mathrm{mg} / \mathrm{kg}$ ), Group 4 (AMS 25 mg/kg/day), Group 5 (AMS 50 mg/kg/day), Group 6 (AMS $100 \mathrm{mg} / \mathrm{kg} /$ day), and Group 7 (AMS $200 \mathrm{mg} / \mathrm{kg} /$ day).

2.1.2. Efficacy Study. Forty animals were randomly divided into five groups $(n=8)$ : Group 1 (control), Group 2 (hypertrophy), Group 3 (hypertrophy+25 mg/kg/day), Group 4 (hypertrophy+AMS $50 \mathrm{mg} / \mathrm{kg} /$ day), and Group 5 (hypertrophy+enalapril $10 \mathrm{mg} / \mathrm{kg} /$ day).

2.2. Dosage Information. For safety study, $0.5 \mathrm{ml}$ of virgin corn oil (Group 2), freshly prepared garlic homogenate $250 \mathrm{mg} / \mathrm{kg} /$ day along with $0.5 \mathrm{ml}$ of corn oil (Group 3), and AMS 25, 50, 100, and $200 \mathrm{mg} / \mathrm{kg}$ (Groups 4, 5, 6, and 7) dissolved in $0.5 \mathrm{ml}$ of corn oil were administered orally for 30 days. For efficacy study, $0.5 \mathrm{ml}$ of corn oil was orally administered as vehicle in three groups (Group 1, Group 2, and Group 5) while AMS (25 and $50 \mathrm{mg} / \mathrm{kg} /$ day) dissolved in $0.5 \mathrm{ml}$ was orally administered in two groups (Groups 3 and 4). Group 5 received $10 \mathrm{mg} / \mathrm{kg}$ of enalapril orally.

2.3. Electrocardiography. Rats were anesthetized in supine position by gaseous anesthesia (isoflurane $2 \%$ ) coupled with a $100 \%$ oxygen supply. The core body temperature of the animal was maintained at $37^{\circ} \mathrm{C}$ by a controlled heating pad (Homeothermic Blanket Control unit, Harvard Apparatus ${ }^{\circledR}$ ). As per the manufacturer's instructions, 15 minutes of ECG was recorded to each animal on Power Lab 26T (ADInstruments, Australia) and the acquired data was analyzed on LabChart 8 software.

2.4. Serum Biochemical Parameters. Safety study animals were subjected to retroorbital bleeding under gaseous anesthesia. Blood samples were kept at room temperature for $1 \mathrm{hr}$ followed by centrifugation at $3,000 \mathrm{~g}$ for 30 minutes at $4^{\circ} \mathrm{C}$. Serum glutamic oxaloacetic transaminase (SGOT), 
serum glutamic pyruvic transaminase (SGPT), creatinine kinase-myocardium bound (CK-MB), and alkaline phosphatase were measured by a semi autoanalyzer.

2.5. Single-Dose Pharmacokinetics of Allylmethylsulfide. To study the pharmacokinetics of AMS, SD rats were used. AMS $100 \mathrm{mg} / \mathrm{kg}$ single dose was administered orally, and subsequently, blood samples were collected at $0,0.25,0.5,1$, $2,4,8,12,24,36$, and $48 \mathrm{hrs}$. Post 30 minutes of sample collection, serum was separated by centrifugation at $600 \mathrm{~g}$ for 20 minutes at $4^{\circ} \mathrm{C}$ and stored at $-80^{\circ} \mathrm{C}$ for further analysis.

2.5.1. Metabolite Extraction. For sample preparation, $100 \mu \mathrm{l}$ of serum was mixed with $100 \mu \mathrm{l}$ of LC-MS grade methanol and vortexed for $10 \mathrm{~min}$ at room temperature. Further, the sample was incubated on ice for $15 \mathrm{~min}$ and centrifuged at $16000 \mathrm{~g}$ for $20 \mathrm{~min}$ at $4^{\circ} \mathrm{C}$. The resultant supernatant was filtered with a $0.2 \mu \mathrm{m}$ filter.

2.5.2. Metabolomics Measurement. For standard curve, AMS (Cas. No. 10152-76-8, Sigma-Aldrich), AMSO (Cas. No. 21892-75-1, EPTES, Food and Flavor Analytical), and $\mathrm{AMSO}_{2}$ (Cas. No. 16215-14-8, Sigma-Aldrich) were spiked in control serum and the earlier mentioned extraction procedure was followed. All data were acquired on the orbitrap fusion mass spectrometer equipped with a heated electrospray ionization (HESI) source. Data were acquired on a positive mode at 120,000 resolution in full-scan MS1. We used a spray voltage of 4000 for positive. Sheath gas and auxiliary gas were set to 42 and 11, respectively. The mass scan range was $50-500 \mathrm{~m} / \mathrm{z}$, AGC (automatic gain control) target at 400000 ions, and the maximum injection time was $200 \mathrm{~ms}$ for MS. Extracted metabolites were separated on UPLC ultimate 3000 using an HSST3 column $(100 \times 2.1 \mathrm{~mm}$ i.d, 1.9 micrometer, Waters Corporation) maintained at $40^{\circ} \mathrm{C}$ temperature. Mobile phase A was methanol with $0.1 \%$ formic acid, and mobile phase B was water with $0.1 \%$ formic acid. The elution gradient is used as follows: $0 \mathrm{~min}, 1 \% \mathrm{~B} ; 1 \mathrm{~min}$, $15 \% \mathrm{~B} ; 4 \mathrm{~min}, 35 \% \mathrm{~B} ; 7 \mathrm{~min}, 95 \% \mathrm{~B} ; 9 \mathrm{~min}, 85 \% \mathrm{~B} ; 10 \mathrm{~min}$, $1 \% \mathrm{~B}$; and $14 \mathrm{~min}, 1 \% \mathrm{~B}$. The flow rate of $0.3 \mathrm{ml} / \mathrm{min}$, and the sample injection volume were 5 microliters.

2.5.3. Data Processing. All acquired data has been processed using Progenesis QI for metabolomics (Waters Corporation) software using the default setting. The untargeted metabolomics workflow of Progenesis QI was used to perform retention time alignment, feature detection, deconvolution, and elemental composition prediction. Identification of metabolites has been done based on the match of accurate mass and the retention time of purchased standards. Relative intensity of the corresponding metabolites has been used for quantification. PKSolver a freely available add-in program for Microsoft Excel was used for pharmacokinetic parameters as mentioned [23].

2.6. In Vivo Cardiac Hypertrophy Model. Isoproterenol $(\sim 5 \mathrm{mg} / \mathrm{kg} /$ day $)$ prepared in $0.001 \%$ ascorbic acid solution was delivered by ALZET $^{\circledR}$ osmotic minipump (model \#2002) as per the manufacturer's instructions. Briefly, rats were anesthetized with gaseous anesthesia (isoflurane $2 \%$ ) coupled with a $100 \%$ oxygen supply. The core body temperature of the animal was maintained at $37^{\circ} \mathrm{C}$ by a controlled heating pad (Homeothermic Blanket Control unit, Harvard Apparatus $\left.{ }^{\circledR}\right)$. Hairs on the dorsal side below the neck are removed by depilatory cream, and a small incision is made to accommodate the sterile minipump charged with isoproterenol solution subcutaneously. Finally, 4-0 silk sutures are used to close the incision. Control animals received osmotic minipump filled with $0.001 \%$ ascorbic acid alone. Finally, povidone-iodine ointment was applied until complete wound healing is achieved. Minipump (model 2002) dispenses $0.5 \mu \mathrm{l}$ per hour for 14 days.

\subsection{Biochemical Estimation}

2.7.1. Lipid Peroxidation. Lipid peroxidation in the myocardium was measured by the protocol described by Ohkawa et al. [24]. Briefly, an equal amount of tissue is homogenized in $10 \%(w / v)$ of ice-cold $0.05 \mathrm{M}$ potassium phosphate buffer ( $\mathrm{pH}$ 7.4). Each homogenate $(0.2 \mathrm{ml})$ was added to $0.2 \mathrm{ml}$ of $8.1 \%$ SDS, $1.5 \mathrm{ml}$ of $20 \%$ acetic acid, and $1.5 \mathrm{ml}$ of $0.8 \%$ thiobarbituric acid (TBA). Distilled water was added to make up the volume to $4.0 \mathrm{ml}$, and the solution was kept on water bath maintained at $95^{\circ} \mathrm{C}$ for $1 \mathrm{hr}$. Finally, the supernatant was mixed with an equal volume of butanol: pyridine $(15: 1)$ and centrifuged and the optical density of the organic layer was measured at $532 \mathrm{~nm}$. For quantification of malondialdehyde (MDA) formed in the myocardium, we make a standard curve after putting 1,1,3,3-tetraethoxypropane in different concentrations and mixed with the TBARS as mentioned above.

2.7.2. Reduced Glutathione. Reduced glutathione in the myocardium was measured by Ellman's method [25]. Briefly, an equal amount of heart tissue was homogenized in $10 \%$ $(w / v)$ of ice-cold $0.05 \mathrm{M}$ potassium phosphate buffer $(\mathrm{pH}$ 7.4). The resultant homogenate was centrifuged at $15,800 \mathrm{~g}$ for 30 minutes at $4^{\circ} \mathrm{C}$. To deproteinize, $0.5 \mathrm{ml}$ of the above supernatant was mixed with $0.5 \mathrm{ml}$ of $5 \%$ trichloro acetic acid (TCA) and centrifuged at 2,300 g for 10 minutes. The deproteinized $0.5 \mathrm{ml}$ sample is mixed with $0.25 \mathrm{ml}$ of dithio-nitro-benzoic-acid (DTNB) and $1.5 \mathrm{ml}$ of $0.3 \mathrm{M}$ disodium hydrogen phosphate. Finally, the optical density of the mixture was measured at $412 \mathrm{~nm}$. The readout of the sample was normalized by total protein present as measured by the bicinchoninic acid assay method (Thermo Scientific).

2.7.3. Catalase Estimation. Myocardial catalase was estimated by the method as described by Aebi [26]. Briefly, tissue samples were homogenized as mentioned earlier. About $20 \mu \mathrm{l}$ of tissue supernatant was mixed with $0.5 \mathrm{ml}$ of $50 \mathrm{mM}$ phosphate buffer ( $\mathrm{pH} 7.0$ ), and finally, $0.25 \mathrm{ml}$ of $30 \mathrm{mM} \mathrm{H}_{2} \mathrm{O}_{2}$ is added, and change in the absorbance at $240 \mathrm{~nm}$ was recorded for 1.5 minutes with a 15 -second interval. Catalase activity is expressed as the decomposition of $\mathrm{H}_{2} \mathrm{O}_{2} / \mathrm{min} / \mathrm{mg}$ of protein.

2.7.4. Superoxide Dismutase. Total superoxide dismutase activity is measured as per the manufacturer's protocol using the Sigma-Aldrich (19160-1KT-F) kit. 
TABle 1: Primers used in RT-PCR analysis.

\begin{tabular}{lcc}
\hline Gene & Forward primer & Reverse primer \\
\hline ANP & AGCGAGCAGACCGATGAAGG & AGCCCTCAGTTTGCTTTTCA \\
Beta MHC & TGGAGCTGATGCACCTGTAG & ACTTCGTCTCATTGGGGATG \\
RPL32 & AGATTCAAGGGCCAGATCCT & CGATGGCTTTTCGGTTCTTA \\
\hline
\end{tabular}

2.8. Immunoblotting. Approximately $50 \mathrm{mg}$ of myocardial tissue is homogenized in $1 \mathrm{ml}$ of RIPA buffer containing (1x) protease and phosphatase inhibitors. The homogenate is centrifuged at $13,500 \mathrm{~g}$ for $20 \mathrm{~min}$ at $4^{\circ} \mathrm{C}$. Protein concentration in the supernatant is measured by the the bicinchoninic acid assay method (Thermo Scientific). Sample preparation is done in Laemmli buffer using an equal amount of protein. For electrophoresis, protein is resolved on $10 \%$ SDS-polyacrylamide gel prepared by the TGX stain-free kit (Bio-Rad). Methanol-activated $0.2 \mu \mathrm{m}$ pore size (Thermo Scientific) polyvinylidene difluoride (PVDF) membrane is used for protein transfer after electrophoresis. To avoid nonspecific binding of antibodies, membranes are blocked with $5 \%$ bovine serum albumin (BSA) prepared in tris-buffered saline (TBS) containing $0.1 \%$ Tween 20 for $60 \mathrm{~min}$ at room temperature. Primary antibody incubation is done overnight at $4^{\circ} \mathrm{C}$. To remove the unbound primary antibody, the membrane is washed with $1 \mathrm{x}$ TBST thrice with $5 \mathrm{~min}$ interval each.

The specific HRP-labelled secondary antibody is incubated at room temperature for $60 \mathrm{~min}$. Further, the membrane is washed with TBST thrice and finally, the signal is recorded using the Gel Doc XR system (Bio-Rad) with West Dura Pico kit (Thermo Scientific). The following antibodies were used in the study: beta MHC (Abcam; ab50967), MnSOD (Abcam; ab137037), catalase (Abcam; ab52477), caspase 3 (Cell Signaling; 9665), caspase 7 (Cell Signaling; 12827), caspase 9 (Cell Signaling; 9508), MMP2 (Abcam; ab86607), MMP9 (Abcam; ab38898), TIMP3 (Cell Signaling; 5673), and GAPDH antibody (Cell Signaling; 2118). Measured protein expression was normalized to GAPDH as a housekeeping protein.

2.9. Gene Expression. Total RNA was isolated from the left ventricular tissue by TRI reagent (Sigma-Aldrich) as per the manufacturer's protocol. The purity and concentration of RNA were measured by a NanoDrop spectrophotometer (Thermo Scientific). Following DNase treatment, reverse transcriptase reaction was performed by SuperScript-III Reverse Transcriptase (Takara, USA) for cDNA synthesis from $2 \mu \mathrm{g}$ of RNA. Primer sequences for real-time polymerase chain reaction (RT-PCR) were designed from the published sequences available in the public domain. RT-PCR was performed on Roche Light Cycler using the SYBR Green mix (Takara, USA). The data obtained were normalized to RPL32 expression as a reference gene. The following primer sequences were used in the study as mentioned in Table 1.

2.10. Histopathology. Immediately after sacrifice of the whole heart, kidney and liver tissues were excised and cleaned with ice-cold PBS to remove blood clot. Histopathology samples were stored in freshly prepared $10 \%$ phosphate-buffered formalin. Masson's trichrome and haematoxylin-eosin stains were used to stain $5 \mu \mathrm{m}$ thick sections prepared from the paraffin block. To examine the histopathological changes, the Nikon Eclipse Ti microscope was used.

2.11. Cell Culture and Treatments. The rat cardio myoblast (H9c2) cell line was procured from ATCC ${ }^{\circledR}$ (USA) and was cultured in Dulbecco's Modified Eagle Media, (Cat. No. SH30243.01, HyClone ${ }^{\mathrm{TM}}$, GE Life Sciences) containing (4 mM L-glutamine and $45000 \mathrm{mg} / \mathrm{L}$ glucose and sodium pyruvate) and supplemented with $10 \%$ Fetal Bovine Serum (Cat. No. SH30071.03, HyClone ${ }^{\mathrm{TM}}$, GE Life Sciences). Cell culture was maintained at $37^{\circ} \mathrm{C}$ in a $5 \% \mathrm{CO}_{2}$ incubator (HERACELL VIOS 160I, Thermo Scientific). For flow cytometry and confocal imaging, $0.2 \%$ ethanol was added to the control group. The hypertrophy group was treated with $10 \mu \mathrm{m}$ isoproterenol (Sigma-Aldrich) along with $0.2 \%$ ethanol, and the treatment group received $50 \mu \mathrm{m}$ AMS along with $10 \mu \mathrm{m}$ isoproterenol. In every experiment, it is made sure that the final volume of ethanol did not exceed $0.2 \%$. During $72 \mathrm{hrs}$ of the abovementioned treatments, H9c2 cells were grown in DMEM containing 1\% FBS with intermittent medium rechange at every $24 \mathrm{hrs}$.

2.12. ROS Detection by Flow Cytometry and Immunostaining. Intracellular ROS is measured by BD FACSCanto ${ }^{\mathrm{TM}}$ II (BD Biosciences, US). Briefly, following $72 \mathrm{hrs}$ of earlier mentioned treatments, $10 \mu \mathrm{m}$ dichlorodihydrofluorescein diacetate (Cat. No. D399, Invitrogen, San Diego, CA) is incubated for 30 minutes at $37^{\circ} \mathrm{C}$. Cells were trypsinized with $1 \mathrm{x}$ Trypsin-EDTA (Cat. No. CC5027.010L, Cell Clone ${ }^{\mathrm{TM}}$ ) and centrifuged at $210 \mathrm{~g}$ for 10 minutes with two times of PBS washing. The results were analyzed by Flow $\mathrm{Jo}^{\mathrm{TM}}$ software for Windows Version V10, Ashland.

For immunostaining, we followed the previously described protocol [27], Briefly, following $72 \mathrm{hrs}$ of earlier mentioned treatment, $10 \mu \mathrm{m}$ DCFDA was incubated for 30 minutes at $37^{\circ} \mathrm{C}$ and washed twice with $1 \mathrm{x}$ PBS. H9c2 cells on coverslip are fixed with $10 \%$ menthol prepared in $1 x$ PBS for 5 minutes at room temperature. Finally, after two times of PBS washing, the coverslips were mounted on a glass slide with mounting media (Cat. No. H-1200, VECTASHIELD, Vector Laboratories, Inc., Burlingame, CA) containing DAPI. Fluorescent images were captured with a FV 3000 (OLYMPUS, Life Science Solutions) laser scanning confocal microscope. The images were analyzed by FIJI (NIH-Image J) software. 


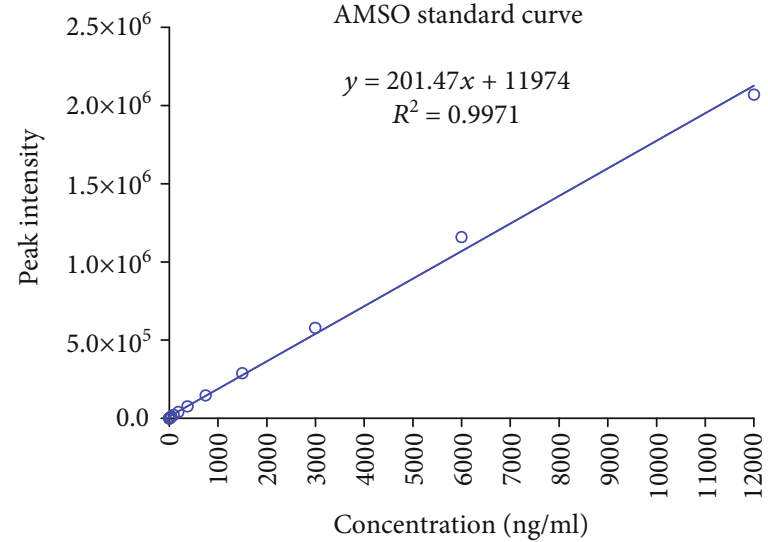

(a)

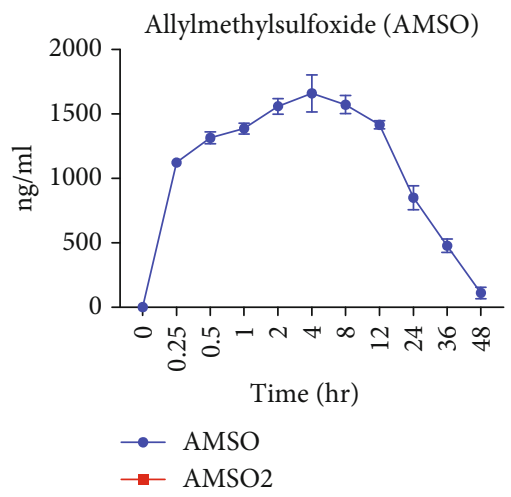

(c)

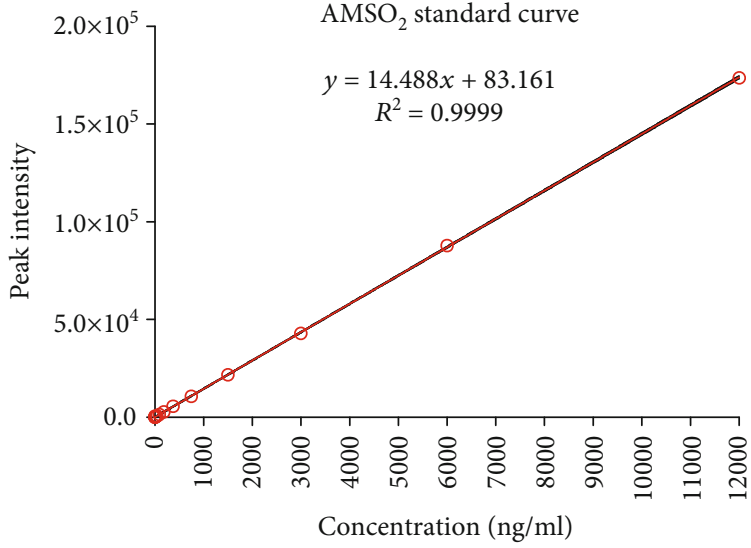

(b)
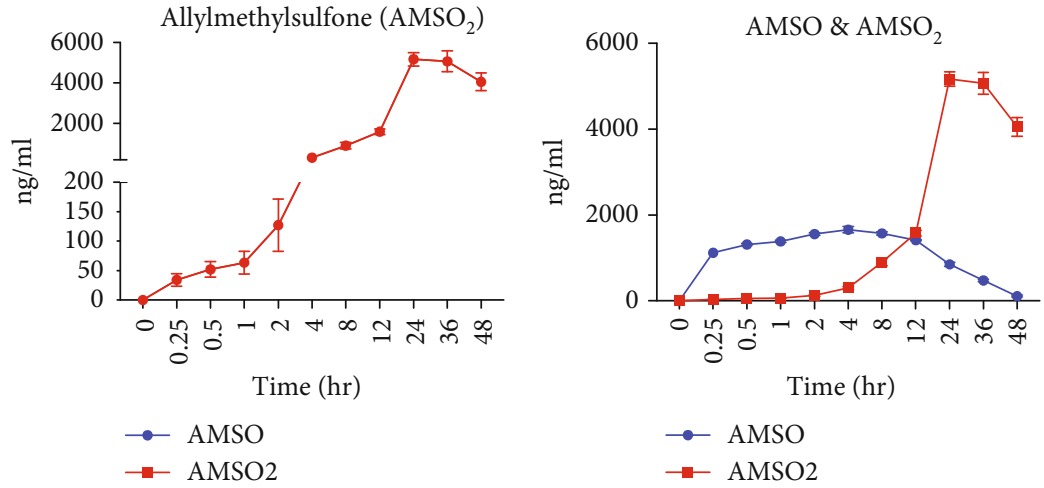

(e)

\begin{tabular}{lccc}
\hline & Parameters & AMSO & AMSO $_{2}$ \\
\hline 1 & $C_{\text {max }}(\mathrm{ng} / \mathrm{ml})$ & $16022.81 \pm 543.57$ & $44089.33 \pm 1378.92$ \\
2 & $T_{\max }(\mathrm{hr})$ & $5 \pm 1$ & $24 \pm 0$ \\
3 & $T_{1 / 2}(\mathrm{hr})$ & $10.33 \pm 1.45$ & $63.84 \pm 7.03$ \\
4 & $\mathrm{AUC}_{0-\mathrm{t}}(\mathrm{ng} / \mathrm{ml} * \mathrm{~h})$ & $412545.01 \pm 5919.22$ & $1371732.06 \pm 44452.43$ \\
5 & $\lambda_{\mathrm{z}}(1 / \mathrm{hr})$ & $0.071 \pm 0.01$ & $0.011 \pm 0.0010$ \\
\hline
\end{tabular}

(f)

FIGURE 1: Effect of Allylmethylsulfide on pharmacokinetic parameters. (a) Standard curve of Allylmethylsulfoxide (AMSO). (b) Standard curve of Allylmethylsulfone $\left(\mathrm{AMSO}_{2}\right)$. (c, d) Concentration vs time graph of AMSO and $\mathrm{AMSO}_{2}$. (e) Cumulative representation of graphs c and d. (f) Pharmacokinetic parameters of AMSO and $\mathrm{AMSO}_{2}$. Maximum serum concentration $\left(C_{\max }\right)$, time taken to reach maximum serum concentration $\left(T_{\max }\right)$, elimination half-life $\left(T_{1 / 2}\right)$, area under curve from time " 0 " to time " $t$ " $\left(\mathrm{AUC}_{0-\mathrm{t}}\right)$, and terminal elimination rate constant $\left(\lambda_{\mathrm{z}}\right)$. Data were represented as mean \pm SEM $(n=4)$.

2.13. Caspase 3/7 Assay in H9c2 Cell. H9c2 cardio myoblasts were grown on a glass coverslip and treated with the abovementioned doses for $72 \mathrm{hrs}$. Caspase $3 / 7$ green fluorescent reagent (Cat. No. C10423, CellEvent ${ }^{\mathrm{TM}}$, Invitrogen) is a four-amino acid peptide (DEVD) attached to a nucleic acid-binding dye with absorption/emission maxima of $\sim 502 / 530 \mathrm{~nm}$. Activated caspase $3 / 7$ will cleave the DEVD peptide sequence and allow it to bind with the nucleic acid and produce a green signal. Following treatments, $5 \mu \mathrm{m}$ of caspase $3 / 7$ green detection reagent in complete media is incubated for 30 minutes at $37^{\circ} \mathrm{C}$. Finally, the media is removed and washed with 1x PBS. Further, to fix the cells, $4 \%$ paraformaldehyde was used for 15 minutes. Coverslips are mounted on a glass slide with mounting media added with nuclei counter stain DAPI and imaged using a FV 3000 machine. For analysis, mean fluorescence in the nuclei region was considered by FIJI software.

2.14. MTT Assay. In vitro AMS toxicity is determined by methyl thiazolyl tetrazolium (MTT) assay. Briefly, cardio myoblasts $(10,000$ cells/well) were seeded in each 96 well plate to attain a $60-70 \%$ confluency. Further, AMS dose range 


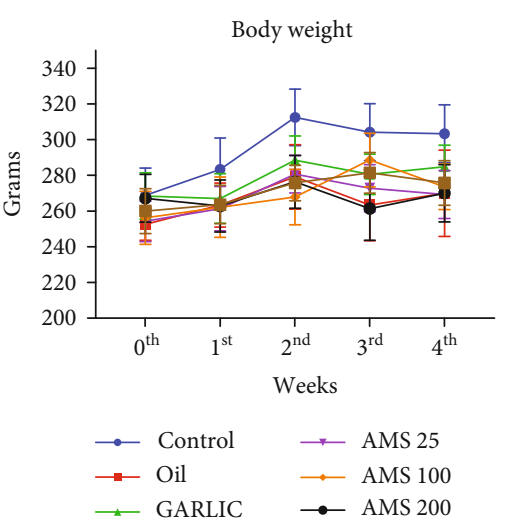

(a)

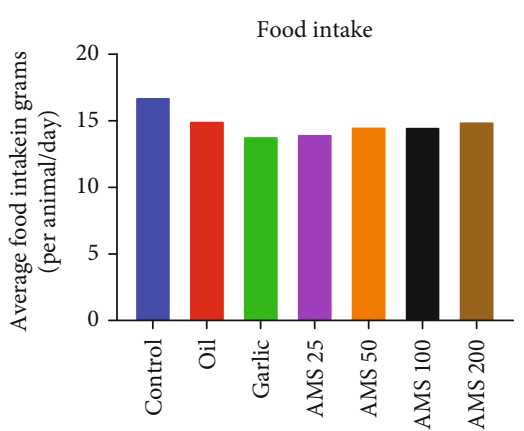

(b)

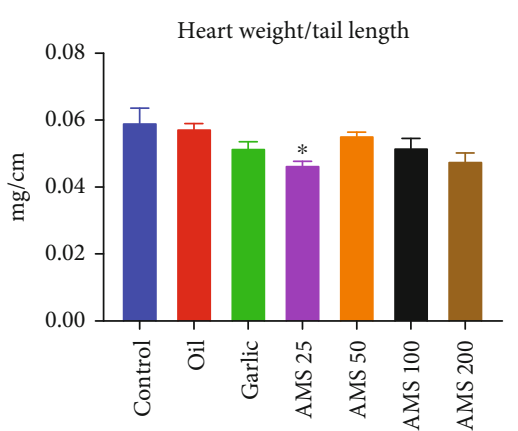

(c)

\begin{tabular}{lccccccc}
\hline Parameter & Control & Oil & Garlic & AMS 25 & AMS 50 & AMS 100 & AMS 200 \\
\hline Heart rate & $339.5 \pm 6.215$ & $347.4 \pm 13.54$ & $340.4 \pm 15.38$ & $300.2 \pm 15.52$ & $332.6 \pm 18.85$ & $316 \pm 13.11$ & $323.3 \pm 9.308$ \\
RR interval & $0.1771 \pm 0.0031$ & $0.1735 \pm 0.006279$ & $0.1674 \pm 0.0119$ & $0.1942 \pm 0.0098$ & $0.1821 \pm 0.0096$ & $0.191 \pm 0.008$ & $0.1863 \pm 0.0054$ \\
QRS interval & $0.02477 \pm 0.003$ & $0.01956 \pm 0.0014$ & $0.01887 \pm 0.001$ & $0.02092 \pm 0.001$ & $0.01994 \pm 0.004$ & $0.0174 \pm 0.002$ & $0.0131 \pm 0.0015$ \\
QT interval & $0.0568 \pm 0.0048$ & $0.0606 \pm 0.0114$ & $0.0573 \pm 0.0090$ & $0.0706 \pm 0.0117$ & $0.0600 \pm 0.0042$ & $0.0714 \pm 0.004$ & $0.067 \pm 0.0108$ \\
QT(c) & $0.1354 \pm 0.011$ & $0.1454 \pm 0.02633$ & $0.1388 \pm 0.0183$ & $0.1585 \pm 0.0283$ & $0.1363 \pm 0.0125$ & $0.1253 \pm 0.011$ & $0.1432 \pm 0.0281$ \\
\hline
\end{tabular}

(d)

FIGURE 2: Effect of Allylmethylsulfide on the (a) body weight, (b) food intake, (c) heart weight to tail length ratio, and (d) electrocardiogram (ECG) parameters. Data were represented as mean \pm SEM, $n=5$ for ECG and $n=8$ for other parameters. ${ }^{*} p<0.05$ vs control.

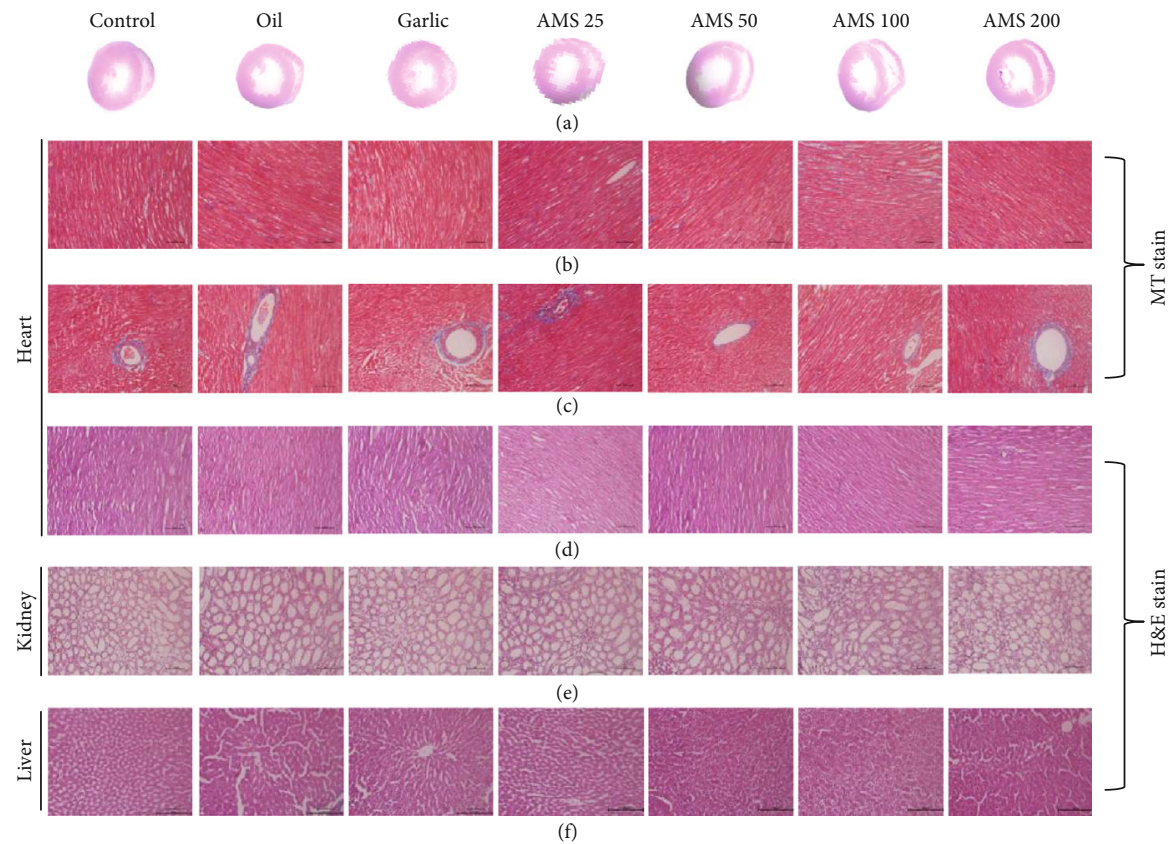

FIgure 3: Effect of AMS on histopathology. (a) Transverse section of the heart representing the ventricular diameter. (b, c) Masson's trichrome staining of the heart tissue representing interstitial and perivascular fibrosis, respectively. (d-f) Haematoxylin and eosin stain of the heart, kidney, and liver.

$(100 \mathrm{~nm}$ to $500 \mu \mathrm{m})$ in ethanol was treated for $24 \mathrm{hrs}$ and then incubated with $1 \mathrm{mg} / \mathrm{ml}$ of MTT for $4 \mathrm{hrs}$ in complete media. During MTT incubation, live cells form purplecolored formazan crystals. Unused MTT in the supernatant was removed, and media was replaced with $50 \mu \mathrm{l}$ of dimethyl sulfoxide (DMSO), and then incubated for 30 minutes at $37^{\circ} \mathrm{C}$ to dissolve the crystals. Finally, absorbance at $570 \mathrm{~nm}$ was recorded on a microplate reader (Molecular Devices). 


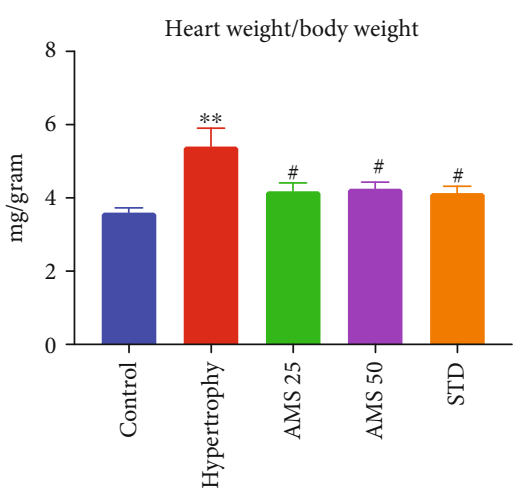

(a)

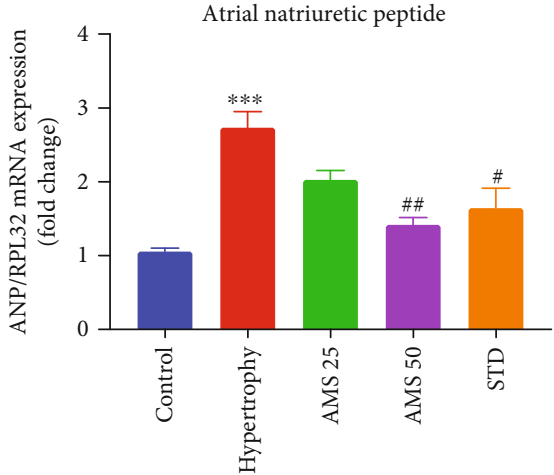

(b)

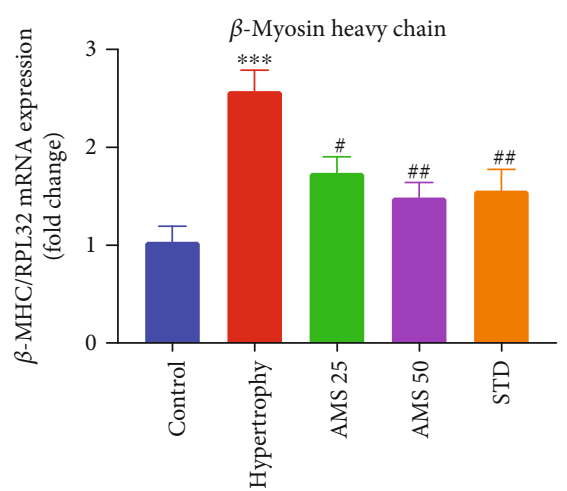

(c)

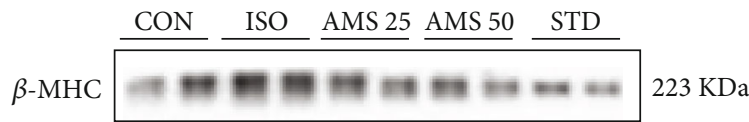

GAPDH

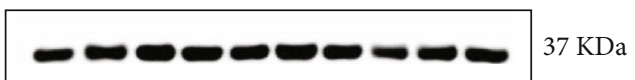

(d)

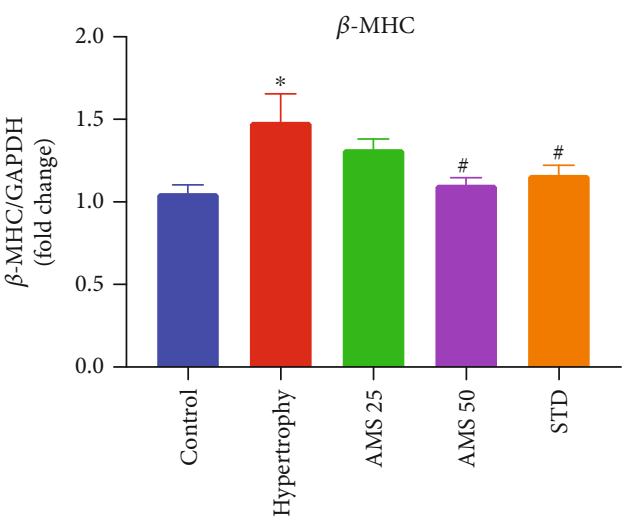

(e)

FIgURE 4: Effect of AMS on cardiac hypertrophy markers. (a) Heart weight to body weight ratio. (b) mRNA expression of atrial natriuretic peptide (ANP). (c) mRNA expression of beta myosin heavy chain $(\beta$-MHC). (d) Representative western blot images of $\beta$-MHC and GAPDH. (e) Densitometric analysis of $\beta$-MHC. mRNA expression data were normalized to the expression of the reference gene, RPL32. Protein expression data were normalized with the reference protein expression, GAPDH. Data were expressed as mean \pm SEM, $(n=5$ for mRNA expression and $n=4$ for protein expression). ${ }^{*} p<0.05,{ }^{* *} p<0.01,{ }^{* * *} p<0.001$ vs control and ${ }^{\#} p<0.05$, ${ }^{\# \#} p<0.01$ vs hypertrophy.

The effect of AMS on H9c2 proliferation was expressed as relative percentage viability. Percent viability $=(\mathrm{OD}$ of treatment/OD of control) $* 100$.

2.15. Statistical Analysis. Data in the present study is reported as the mean \pm standard error of the mean (S.E.M). Mean differences among the study group were analyzed by one-way analysis of variance (ANOVA), followed by the Bonferroni multiple comparison test. A significance level is assumed if $p<0.05$. Statistical analysis was performed in GraphPad
Prism 8.2.1 (279) (Graph Pad Software Inc., San Diego, CA, USA).

\section{Results}

3.1. Allylmethylsulfide Is Rapidly Metabolized into Allylmethylsulfoxide and Allylmethylsulfone. To study the pharmacokinetics of AMS, a single dose of $100 \mathrm{mg} / \mathrm{kg}$ was administered orally. We have observed that AMS is rapidly metabolized into $\mathrm{AMSO}$ and $\mathrm{AMSO}_{2}$ in the physiological 


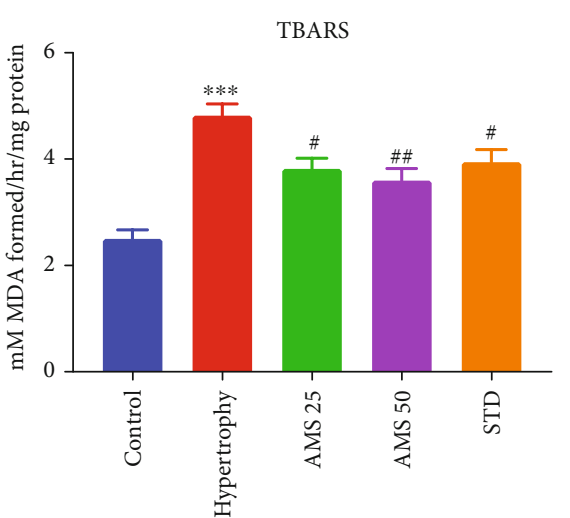

(a)

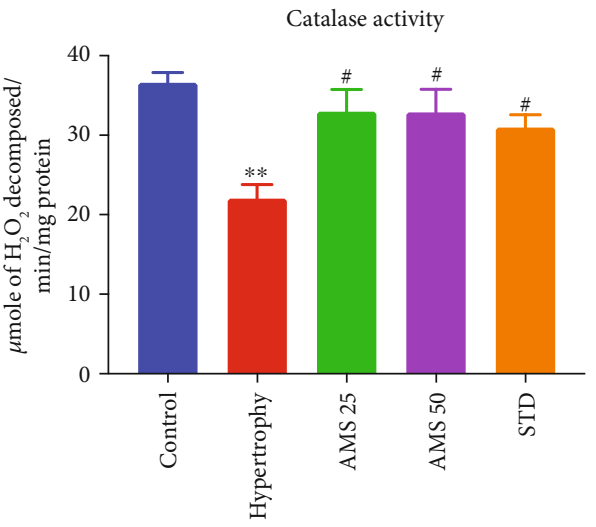

(c)

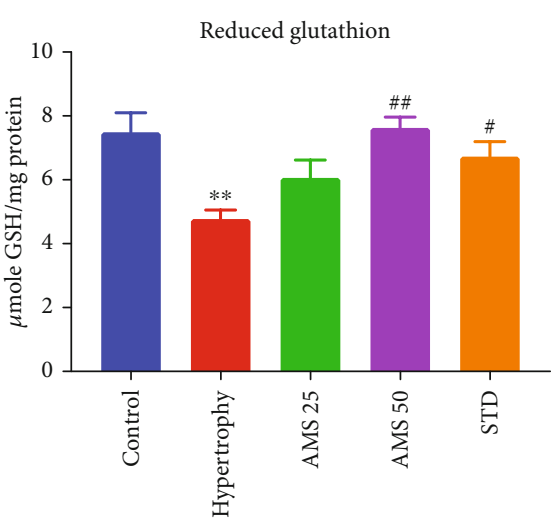

(b)

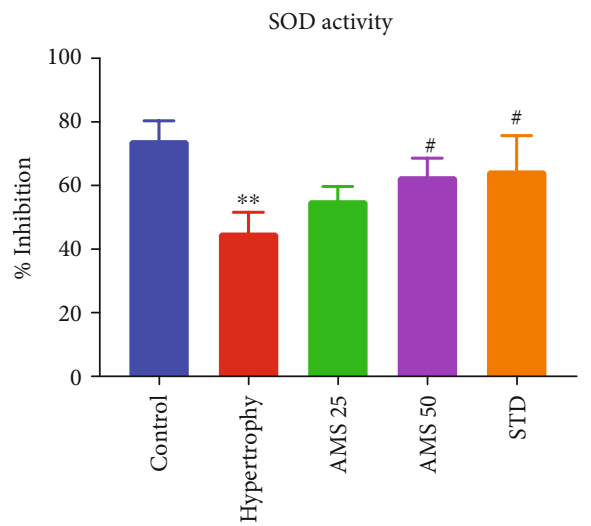

(d)

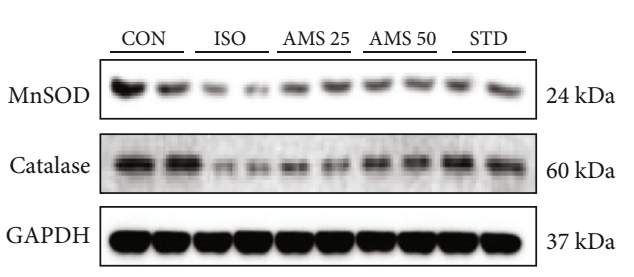

(e)

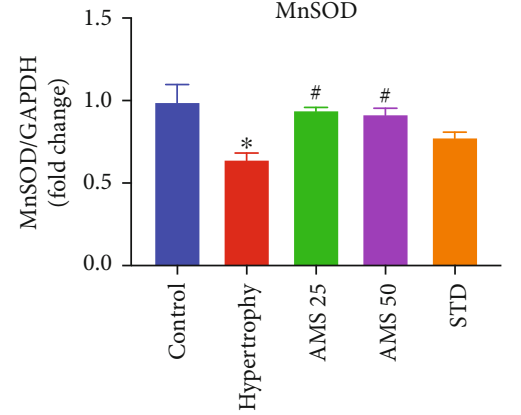

(f)

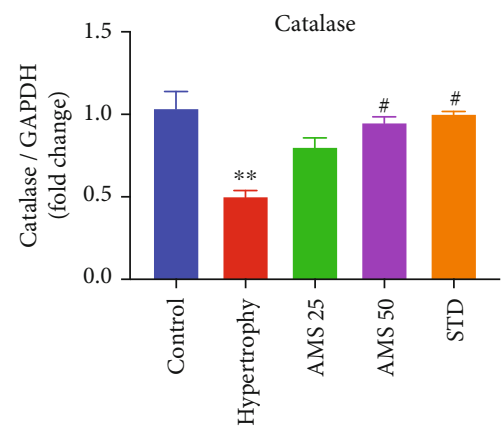

(g)

FIGURE 5: Effect of AMS on biochemical parameters and endogenous antioxidants. (a) Thiobarbituric acid reactive substances (TBARS). (b) Reduced glutathione (GSH). (c) Catalase activity. (d) Super oxide dismutase activity (SOD). (e) Representative western blot images of MnSOD, catalase, and GAPDH. (f) Densitometric analysis of manganese superoxide dismutase (MnSOD). (g) Densitometric analysis of catalase expression. Protein expression data were normalized with the reference protein expression, GAPDH. Data were expressed as mean \pm SEM, $(n=5$ for biochemical parameters and $n=4$ for protein expression $) .{ }^{*} p<0.05,{ }^{* *} p<0.01$, and ${ }^{* * *} p<0.001$ vs control group and ${ }^{\#} p<0.05,{ }^{\# \#} p<0.01$ vs hypertrophy.

system. To measure the exact concentration of AMSO and $\mathrm{AMSO}_{2}$ in the serum, peak intensity of the metabolites was extrapolated to the standard curve of the same, respectively (Figures 1(a) and 1(b)). With time, the concentration of AMSO and $\mathrm{AMSO}_{2}$ is gradually increased and showed peak at $5 \mathrm{hrs}$ and $24 \mathrm{hrs}$, respectively (Figures $1(\mathrm{c})-1(\mathrm{e})$ ). Pharmacokinetic parameters, derived from concentration vs time curve by PKsolver, suggests that half-life of AMSO is less (10.33 hrs) compared to $\mathrm{AMSO}_{2}(63.84 \mathrm{hrs})$ (Figure 1(f)).
The $C_{\max }$ for $\mathrm{AMSO}$ and $\mathrm{AMSO}_{2}$ are 16022.81 and $44089.33 \mathrm{ng} / \mathrm{ml}$, respectively (Figure 1(f)).

3.2. Allylmethylsulfide Is Safe in Rats on Chronic Administration. To evaluate the effect of chronic administration of AMS, we have measured the body weight of the animals at every week from the beginning of AMS intervention till 4 weeks. We did not observe any significant change in the body weight in any of our treatment groups 

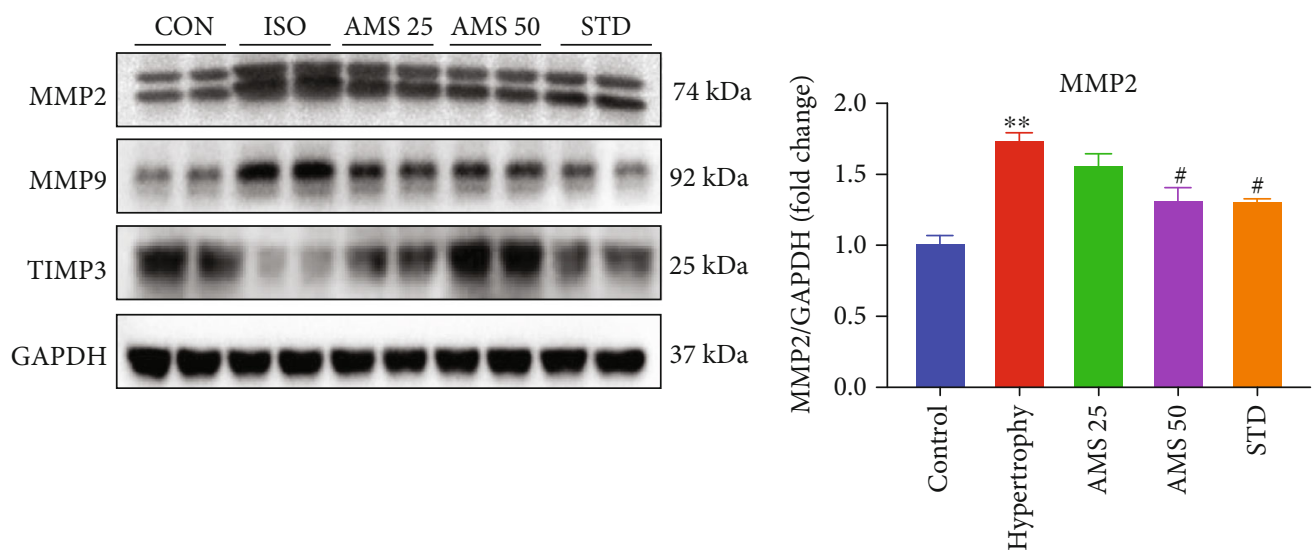

(a)

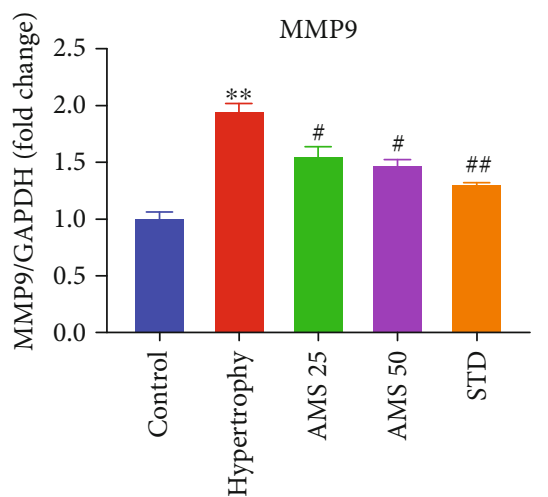

(c)

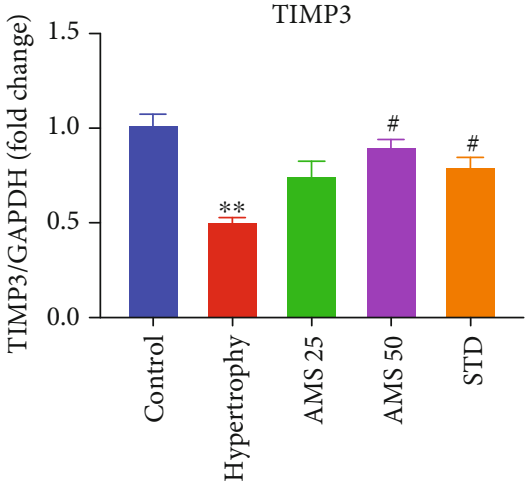

(d)

FiguRE 6: Effect of AMS on extracellular matrix components. (a) Representative western blot images of caspase matrix metalloproteinases (MMPs 2 and 9), tissue inhibitor of matrix metalloproteinase 3 (TIMP3), and GAPDH. (b, c) Densitometric analysis of MMPs 2 and 9. (d) Densitometric analysis of TIMP3. Protein expression data were normalized with the reference protein expression, GAPDH. Data expressed as mean \pm SEM, $(n=4) .{ }^{* *} p<0.01,{ }^{* * *} p<0.001$ vs control group and ${ }^{\#} p<0.05,{ }^{\# \#} p<0.01$ vs hypertrophy.

(Figure 2(a)). Similarly, food consumed by each rat per day (normalized with the number of animals per cage) did not show a major difference between the groups (Figure 2(b)). Except for AMS $25 \mathrm{mg} / \mathrm{kg}$ dose, there was no significant decrease in the heart weigh to tail length ratio compared with other doses (Figure 2(c)). Further, to study the impact to AMS on electrical conduction of the myocardium, we have performed electrocardiogram (ECG), at the end of 30 days of the treatment. We did not observe significant differences in any of the ECG parameters (Figures 2(d)).

3.3. Histopathology and Serum Biomarkers of Vital Organs Remained Normal on Chronic Administration of Allylmethylsulfide. To study the effect of AMS on histopathology of vital organs such as the heart, liver, and kidney, we have stored the tissues immediately after the euthanasia and stained it with MT and H\&E stain. We did not observe any structural difference between any of the treatment groups (Figures 3(a)-3(f)). Before sacrifice, we have collected the serum and measured biomarkers for liver and heart injury. Here, we did not observe a significant difference in serum glutamic oxaloacetic transaminase (SGOT) (Figure S1 (a)), serum glutamic pyruvic transaminase (SGPT) (Figures S1 (b)), creatinine kinase-myocardium bound (CK-MB) (Figure S1 (c)), and alkaline phosphatase (Figure S1 (d)) levels among any of the AMS treatment groups.

3.4. Allylmethylsulfide Ameliorates Isoproterenol-Induced Cardiac Hypertrophy. Isoproterenol-induced cardiac hypertrophy was measured by the heart weight to body weight (HW/BW) ratio at the end of 14 days of AMS cotreatment. We have noticed there is a significant increase in the HW/BW ratio in the diseased group, while with the AMS and enalapril treatment, it was reduced (Figure 4(a)). mRNA expression of the fetal genes such as atrial natriuretic peptide (ANP) (Figure 4(b)) and beta myosin heavy chain ( $\beta$-MHC) (Figure 4(c)) was significantly reduced with the AMS and enalapril treatment in the myocardium. Further, we have measured the protein expression of $\beta$-MHC and noticed that AMS $(50 \mathrm{mg} / \mathrm{kg} /$ day) and enalapril significantly reduced it in the hypertrophied heart (Figure 4(e))

3.5. Allylmethylsulfide Reduced Lipid Peroxidation and Improved Endogenous Antioxidants in Cardiac Hypertrophy. We next decided to study the effect of AMS on lipid peroxidation and endogenous antioxidants. Isoproterenol induced a significant increase in the MDA levels as measured by 

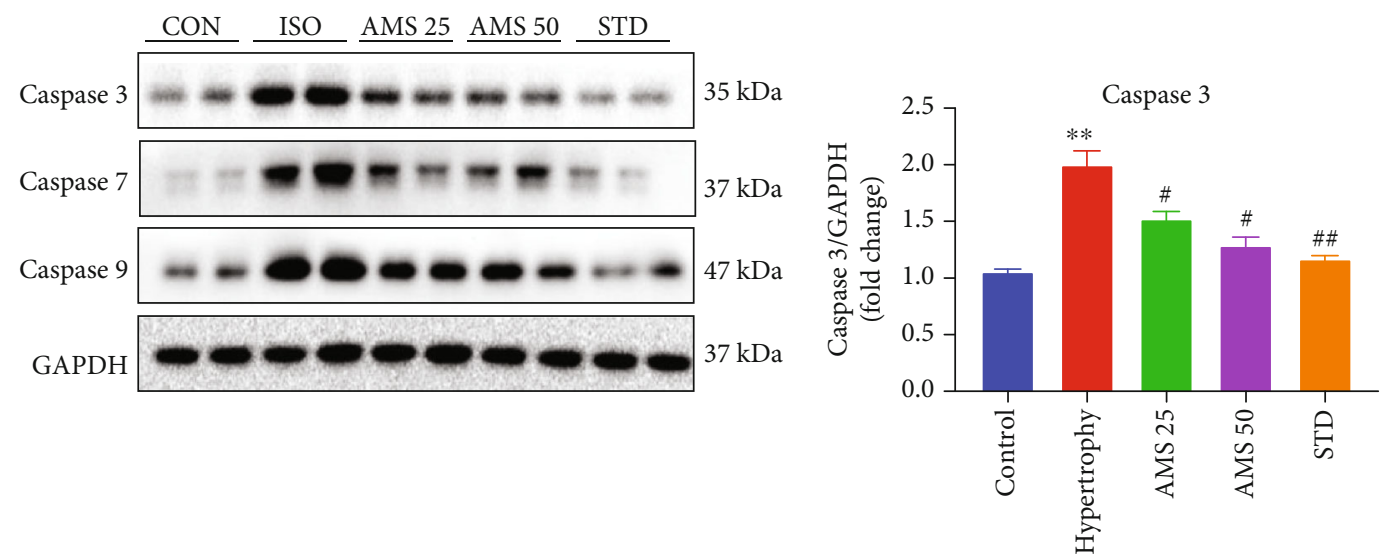

(a)

(b)

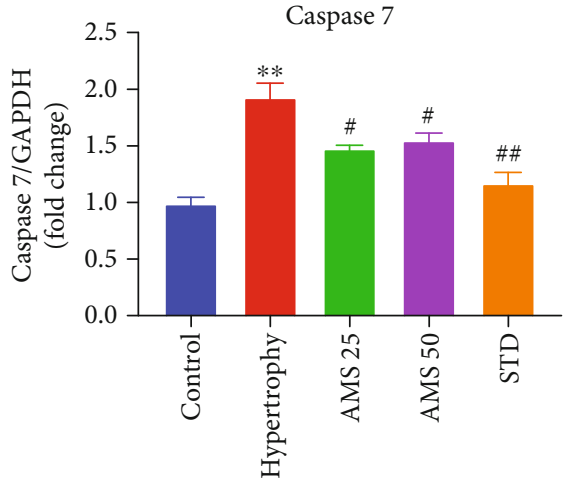

(c)

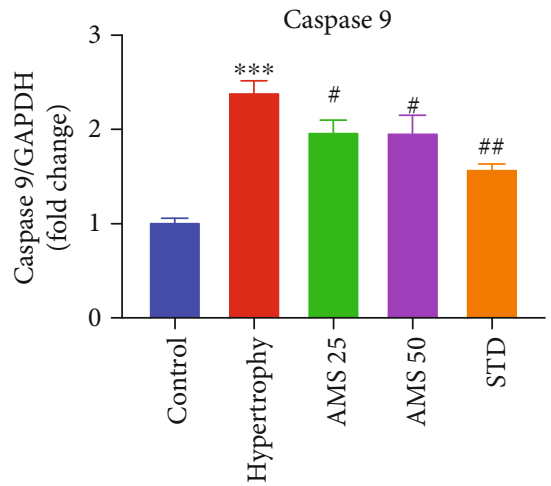

(d)

FIGURE 7: Effect of AMS on caspases. (a) Representative western blot images of caspase 3, caspase 7, caspase 9, and GAPDH. (b-d) Densitometric analysis of caspases 3, 7, and 9. Protein expression data were normalized with the reference protein expression, GAPDH. Data were expressed as mean \pm SEM, $(n=4) .{ }^{* *} p<0.01,{ }^{* * *} p<0.001$ vs control group and ${ }^{\#} p<0.05,{ }^{\# \#} p<0.01$ vs hypertrophy.

TBARS, and with the AMS (25 and $50 \mathrm{mg} / \mathrm{kg} /$ day) and enalapril treatment, it was reduced significantly (Figure 5(a)). The enzyme levels of endogenous antioxidant such as glutathione (GSH) were reduced with the isoproterenol treatment, and with AMS (50 mg/kg/day) and enalapril, it was preserved (Figure 5(b)). Similarly, decreased catalase and superoxide dismutase (SOD) activity in isoproterenol-treated hearts was improved with the AMS and enalapril treatment (Figures 5(c) and 5(d)). To further check the protein expression of catalase and MnSOD, we did immunoblot analysis. We observed that AMS and enalapril treatment increased both of their protein levels in the hypertrophic heart (Figures 5(f) and 5(g)).

3.6. Allylmethylsulfide Ameliorated Reactive Oxygen Species in Isoproterenol-Treated Cardio Myoblast. To corroborate the results of the in vivo study, we have treated H9c2 cardio myoblast for $72 \mathrm{hrs}$. With isoproterenol $(10 \mu \mathrm{m})$ and cotreated with AMS $(50 \mu \mathrm{m})$. Further, we have measured the ROS generation by flow cytometry (Figures S3 (A-D)) and immunofluorescence (Figures S4 (a)-S4(d)). Similar to our in vivo study, we have observed that AMS cotreatment reduced the isoproterenol-induced ROS generation. These two independent experiments confirmed that AMS has a property to reduce the ROS production. We have also checked the viability of the H9c2 cells post 24 hrs treatment with AMS and did not find any significant cytotoxicity (Figure S2).

3.7. Allylmethylsulfide Prevented Extracellular Matrix Damage by Matrix Metalloproteinases. During isoproterenol-induced cardiac hypertrophy, homeostasis of extracellular matrix is perturbed and may result in the activation of matrix metalloproteinases (MMPs). We have observed a significant increase in the protein expression of MMP2 in the hypertrophic group, and with AMS $(50 \mathrm{mg} / \mathrm{kg} /$ day $)$ and enalapril treatment, it was reduced significantly (Figures 6(b)). Similarly, MMP9 expression was also reduced with the AMS (25 and $50 \mathrm{mg} / \mathrm{kg} /$ day) and enalapril treatment (Figure 6(c)). Tissue inhibitor of matrix metalloproteinases (TIMP) modulates the activity of MMPs. We have noticed a reduction of TIMP3 in the isoproterenol-treated heart. However, AMS $(50 \mathrm{mg} / \mathrm{kg} /$ day) and enalapril pretreatment preserved the TIMP3 expression in the isoproterenol-treated heart (Figure 6(d)).

3.8. Allylmethylsulfide Reduced Apoptosis in the IsoproterenolInduced Hypertrophic Heart. We have studied the protein expression of proapoptotic caspases in the hypertrophic heart. We have observed that isoproterenol-induced hypertrophic hearts showed increased expression of caspase 3 (Figure $7(\mathrm{~b})$ ), caspase 7 (Figure $7(\mathrm{c})$ ), and caspase 9 


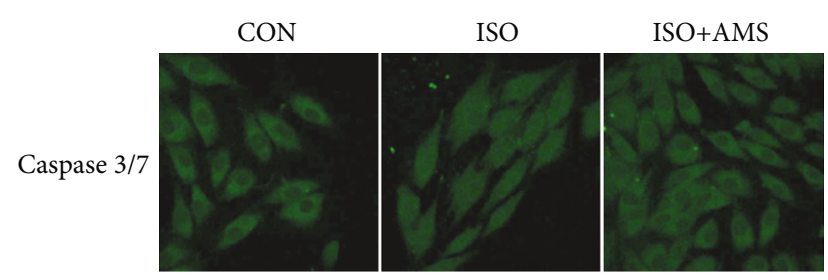

(a)

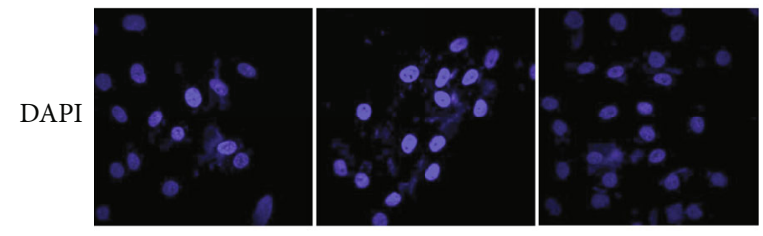

(b)

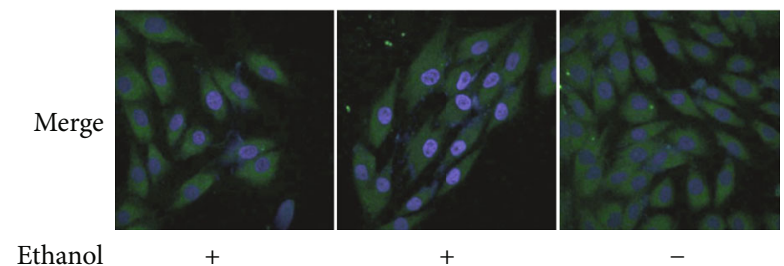

(c)

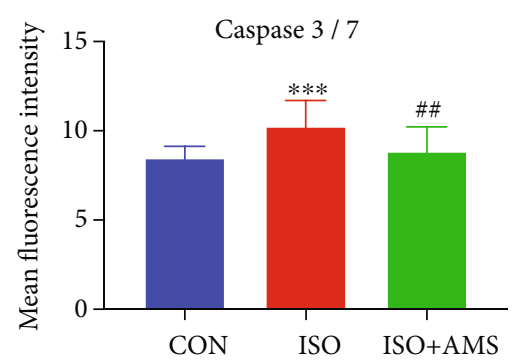

(d)

FIgURE 8: Effect of AMS on caspase 3/7 expression in H9c2 cardio myoblast (a) Representative confocal images of caspase $3 / 7$ expression in the nucleus. (b) Nuclear staining by DAPI. (c) Merged images of DAPI and caspase 3/7. (d) Representative bar graph of mean fluorescence intensity. Data were expressed as mean \pm SEM, $(n=100$ cells/group $) .{ }^{* * *} p<0.001$ vs control (CON) group and ${ }^{\# \#} p<0.01$ vs isoproterenol (ISO).

(Figure $7(\mathrm{~d})$ ), and the same were significantly reduced with the AMS ( 25 and $50 \mathrm{mg} / \mathrm{kg} /$ day) and enalapril treatment.

\subsection{Allylmethylsulfide Reduced Apoptosis Signal in} Isoproterenol-Treated Cardio Myoblast. To corroborate our in vivo finding, we decided to check the effect of AMS on the nuclear expression of caspase 3/7 in isoproterenoltreated $\mathrm{H} 9 \mathrm{c} 2$ cells. We have noticed that there was a significant increase in the green fluorescence of caspase 3/7 in the nuclear portion of isoproterenol-treated cells. However, these signals were reduced in the AMS-cotreated isoproterenol cells (Figures $8(\mathrm{a})-8(\mathrm{~d})$ )

\subsection{Allylmethylsulfide Reduced Fibrosis in the Hypertrophic} Heart. We did histopathology study to check the effect of increased protein expression of matrix metalloproteinases on fibrosis. Gross investigation of the left ventricular diameter showed the presence of hypertrophy in the iso- proterenol group; however, with AMS treatment, we have seen a decrease in the diameter and muscle thickness (Figure 9(a)). To check the fibrosis, we have stained the heart sections with MT staining. Interstitial and perivascular fibrosis were prominent in the isoproterenol-treated heart. However, a reduction of fibrosis was observed with AMS and enalapril treatment (Figures 9(d) and 9(e)). H\&E staining showed a presence of high neutrophil infiltration in the isoproterenol-treated heart. However, AMS and enalapril treatment reduced the extent of neutrophil infiltration (Figures 9(b) and 9(c)).

\section{Discussion}

Both prophylactic and therapeutic effects of garlic in the past have documented numerous promising results. Previously, we have identified that AMS is an active metabolite of garlic and showed a reduction in the cell size in vitro [15]. Pretreatment of AMS ameliorated inflammation in mouse kidney by downregulation of NF- $\kappa$ B signaling [18]. However, the safety and efficacy dose of the AMS, particularly in the cardiac hypertrophy model, are not explored yet. In the current study, we have explored the safety of chronic administration of AMS in rats, single-dose pharmacokinetics, and efficacy of AMS in an isoproterenol-induced cardiac hypertrophy model. Chronic intervention of AMS for 30 days did not show any significant difference in the body weight and food intake. However, the heart weight to tail length ratio was slightly lower with only an AMS $25 \mathrm{mg} / \mathrm{kg}$ dose. Although, at present, we do not know the reason for this change, we have performed ECG to further evaluate any cardiac abnormalities. ECG parameters did not show any significant difference within the dose range. QT prolongation, an important parameter of drug toxicity, did not alter with any of the doses. Next, we checked the effect of AMS on tissue biomarkers in the blood. We have measured SGOT, SGPT, CK-MB, and alkaline phosphatase in the serum at the end of the study. Any damage in the liver can be diagnosed by high SGOT and SGPT levels in the blood [28]. Alkaline phosphatase is present in most of the tissues; however, the bones and liver have the highest amount. The estimation of CK-MB provides information on cardiac muscles [29]. These biomarkers are leaked out from their respective localization into the blood during tissue damage. We did not observe any significant difference in these biomarkers with our treatments. To corroborate these results, we have checked for the histopathology of the heart, liver, and kidney. However, we did not observe any structural differences in the morphology of these vital organs. Single-dose pharmacokinetics suggest that AMS is wellabsorbed through an oral route and rapidly metabolized into AMSO and then subsequently to $\mathrm{AMSO}_{2}$. Presence of AMSO and $\mathrm{AMSO}_{2}$ in the serum for a longer duration may allow a single dose of AMS for an efficacy purpose. Interestingly, we did not observe mortality in any of our treatment groups, these results proved that AMS is a safe molecule in rats. Further, in a concentration range from 0.1 to $500 \mu \mathrm{m}$ of AMS, we did not observe cytotoxicity in rat cardio myoblast (H9c2) cells. 

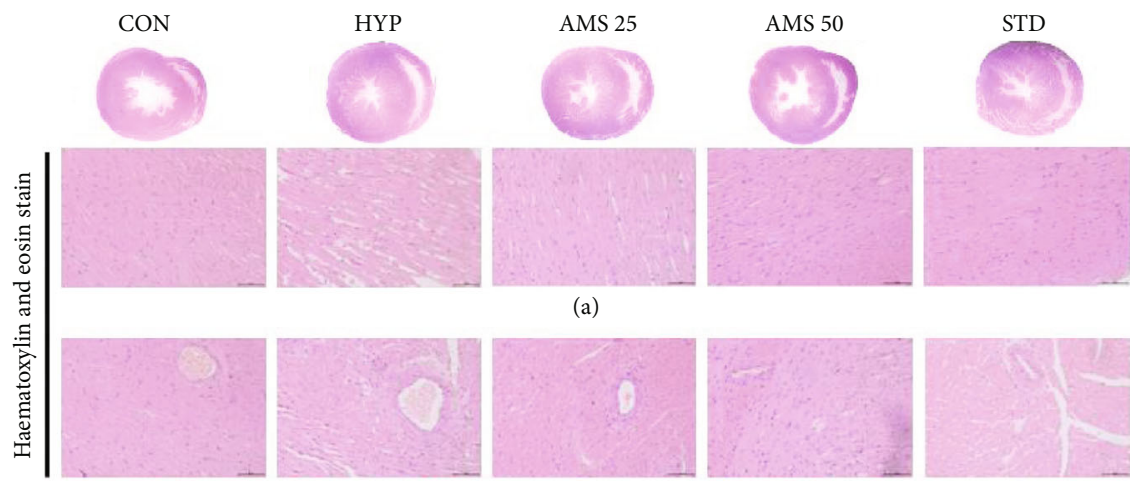

(b)
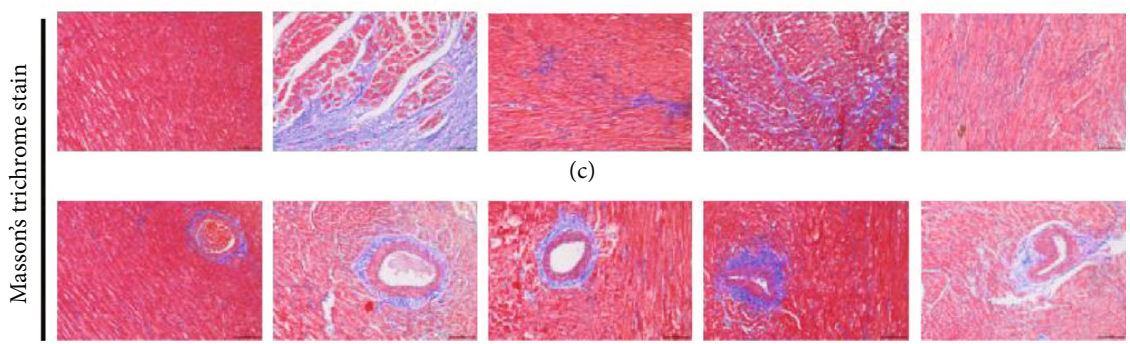

(d)

FIGURE 9: Effect of AMS on isoproterenol-induced hypertrophic heart. (a) Gross transverse section of the heart representing ventricular diameters. (b, c) Haematoxylin and eosin staining of the heart representing neutrophil infiltration in interstitial and perivascular, respectively. (d, e) Masson's trichrome staining of the heart representing interstitial and perivascular fibrosis.

Furthermore, after safety and pharmacokinetic studies, we looked the effect of AMS in the rodent model of cardiac hypertrophy. Isoproterenol-induced cardiac hypertrophy upregulates mRNA expression of fetal genes (ANP and $\beta$-MHC) [30]. In general, they are highly expressed during the early stages of heart development and later remain constitutively expressed in the mature heart. We have observed that the heart weight to body weight ratio, an important parameter of cardiac hypertrophy in animals, and fetal gene expression in heart were significantly reduced in the AMS and enalapril-treated animals. Isoproterenolinduced cardiac hypertrophy is associated with reduced antioxidants and excessive ROS generation. ROS interacts with cellular components and results in lipid peroxidation [31]. Our data showed that there is a significant increase of malondialdehyde (MDA) in hypertrophic hearts, and however, with AMS and enalapril treatment, it was reduced. Antioxidants such as superoxide dismutase (SOD), catalase, glutathione, and glutathione peroxidase play an important role in maintaining the physiological levels of ROS [32]. We have observed decreased activity of antioxidant enzymes in hypertrophic hearts, and however, with AMS and enalapril intervention, it was significantly preserved. We have also found similar results in the protein expression of MnSOD and catalase with AMS and enalapril treatment.

We next thought to corroborate the in vivo findings of oxidative stress with the cellular hypertrophy model. To explore the underlying protective effect of AMS, we have studied the ROS generation in $\mathrm{H} 9 \mathrm{c} 2$ cells. During myocardial stress, excessive ROS production and a compromised antioxidant effect leads to pathological cardiac hypertrophy and ultimately progresses into heart failure [33]. Recent reports suggest that targeting ROS generation could be a better alternative to ameliorate cardiac hypertrophy [34]. In our study, the immunofluorescence and flow cytometric analysis suggest that AMS cotreatment significantly reduced ROS generation in isoproterenol-treated cardio myoblast.

Fibrosis develops due to excessive accumulation of collagen and other ECM components by the differentiation of fibroblast into myofibroblast. Based on the nature of pathological insult, the three types of cardiac fibrosis that develop are reactive interstitial fibrosis, infiltrative interstitial fibrosis, and replacement fibrosis [35]. In our study, the replacement of the myocardium with the fibrous scar was observed in the isoproterenol-induced hypertrophy hearts. However, we have observed a significant reduction of cardiac fibrosis with the treatment of both AMS and enalapril.

Cardiac fibroblast plays a pivotal role in the ECM homeostasis. The major components of ECM include collagen I, collagen III, fibronectin, laminin, and elastin. ECM maintains the structural integrity of cardio myocytes, fibroblast, and coronary arteries within the myocardium and also maintains the electrical signal conduction for rhythmic contractility of the heart. The integrity of the ECM components is mainly regulated by matrix metalloproteinases (MMPs) and their tissue inhibitors (TIMPs) produced by fibroblasts [36]. MMP2 and MMP9 are the important enzymes involved in the degradation of ECM and are involved in various cardiac complications [37]. AMS and enalapril treatment preserved a significant increase in the protein expression of MMP2 and MMP9 in the isoproterenol-induced hypertrophic heart. TIMPs have an important role in preventing the proteolytic degradation of ECM by MMPs. The lack of TIMP3 has resulted in many cardiovascular complications [38]. In our 
study, we have noticed AMS and enalapril improved the protein expression of TIMP3 in hypertrophied hearts.

Cardiac fibrosis resulting from MMP expression was observed in the isoproterenol-induced hypertrophic heart and may lead to cardiomyocyte death, i.e., apoptosis. To investigate the effect of AMS on apoptosis, we have studied the protein expression of caspases. Pathological enlargement of the myocardium with isoproterenol results in activation of programmed cell death, compromised contractile function, and eventually heart failure [39]. Besides apoptosis, caspases play an important role in cardiac inflammation. There are evidence-based studies suggesting the role of caspase 3 and caspase 9 in both cellular and animal models of cardiac hypertrophy [40]. The use of caspase 3 inhibitors holds a promising role in reducing cardiac remodeling [41]. We have observed that caspase 3 , caspase 7 , and caspase 9 protein expressions were significantly increased in hypertrophic hearts; however, with AMS and enalapril, these expressions were reduced. Nuclear expression of caspase $3 / 7$ is a sign of apoptotic induction in cells due to various underlying pathological insults [42]. We have noticed a significant increase in the nuclear expression of caspase 3/7 in isoproterenol-treated $\mathrm{H} 9 \mathrm{c} 2$ cells. However, it was reduced with the AMS cotreatment. The data obtained from in vitro and in vivo studies confirmed that AMS showed some of its beneficial effects in hypertrophic conditions through protection from apoptosis.

\section{Conclusion}

In the present study, we have demonstrated that AMS is a safe molecule in rats. The pharmacokinetic study showed that AMS results into two stable metabolites, i.e., AMSO and $\mathrm{AMSO}_{2}$ in the physiological system. AMS reduced cardiac hypertrophy markers such as fetal gene expression and improved endogenous antioxidants. Isoproterenol-induced cardiac fibrosis and dysregulated ECM deposition in the myocardium were reduced with AMS and enalapril treatment. The only limitation of the efficacy study is that we could not measure the functional parameters of the heart by echocardiography. Overall, our study confirms that AMS is a safe and efficacious molecule for the prevention of cardiac hypertrophy and associated remodeling.

\section{Data Availability}

The data used to support the findings of this study are available from the corresponding author upon request.

\section{Ethical Approval}

All animal studies were approved by the Institutional Animal Ethical Committee (IAEC) of the Translational Health Science and Technology Institute, Faridabad (IAEC/THSTI/2015-4).

\section{Conflicts of Interest}

The authors declare no conflict of interest.

\section{Authors' Contributions}

S.A.M and B.P have performed the animal studies. S.A.M and B.P carried out dosing, biochemical, gene and protein estimation, and analysis of results. U.T performed in vitro studies and analysis of results. S.A.M and Y.K performed the pharmacokinetic study and analyzed the results. S.K.A investigated the histopathology samples. S.A.M and S.K.B conceived and designed the study, interpreted the results, and drafted the manuscript.

\section{Acknowledgments}

The authors are grateful to the Indian Council of Medical Research (ICMR) and Council of Scientific and Industrial Research (CSIR) for providing research fellowship to S.A.M and B.P, respectively. This study was supported by the Translational Health Science and Technology Institute core fund. The authors are thankful to Dr. Md. Jahangir Alam and Mr. Sonu for their assistance in the pharmacokinetic study.

\section{Supplementary Materials}

Figure S1: effect of Allylmethylsulfide on serum biochemical parameters. (a) Serum glutamic oxaloacetic transaminase (SGOT). (b) Serum glutamic pyruvic transaminase (SGPT). (c) Creatinine kinase-myocardium bound (CK-MB). (d) Alkaline phosphatase. Data are represented as mean \pm SEM $(n=4)$. Figure S2: effect of Allylmethylsulfide on cardio myoblast viability. Post $24 \mathrm{hrs}$ of AMS treatment with a dose range from 0.1 to $500 \mu \mathrm{m}$, the fluorescence was analyzed. Figure S3: effect of Allylmethylsulfide on reactive oxygen species (ROS) production in H9c2 cardio myoblast. (a) Representative histogram of control. (b) Representative histogram of isoproterenol. (c) Representative histogram of isoproterenol cotreated with AMS. (d) Representative bar graph of percentage of Alexa Fluor 488-positive cells. Data are expressed as mean $\pm \mathrm{SEM},{ }^{* * *} p<0.001$ vs control (CON) group and ${ }^{\# \#} p<0.01$ vs isoproterenol (ISO). Figure S4: effect of Allylmethylsulfide on reactive oxygen species (ROS) production in $\mathrm{H} 9 \mathrm{c} 2$ cardio myoblast. (a) Representative confocal images of DCFDA. (b) Nuclear staining by DAPI. (c) Merged images of DAPI and DCFDA. (d) Representative bar graph of mean fluorescence intensity. Data are expressed as mean \pm SEM, $(n=100$ cells/group $) .{ }^{* * * *} p<0.0001$ vs control (CON) group and ${ }^{\# \#} p<0.001$ vs isoproterenol (ISO). (Supplementary Materials)

\section{References}

[1] GBD 2017 Causes of Death Collaborators, "Global, regional, and national age-sex-specific mortality for 282 causes of death in 195 countries and territories, 1980-2017: A systematic analysis for the global burden of disease study 2017," Lancet, vol. 392, no. 10159, pp. 1736-1788, 2018.

[2] M. Nakamura and J. Sadoshima, "Mechanisms of physiological and pathological cardiac hypertrophy," Nature Reviews Cardiology, vol. 15, no. 7, pp. 387-407, 2018. 
[3] N. G. Frangogiannis, "The extracellular matrix in myocardial injury, repair, and remodeling," The Journal of Clinical Investigation, vol. 127, no. 5, pp. 1600-1612, 2017.

[4] K. Y. DeLeon-Pennell, C. A. Meschiari, M. Jung, and M. L. Lindsey, "Matrix metalloproteinases in myocardial infarction and heart failure," Progress in Molecular Biology and Translational Science, vol. 147, pp. 75-100, 2017.

[5] L. Li, Q. Zhao, and W. Kong, "Extracellular matrix remodeling and cardiac fibrosis," Matrix Biology, vol. 68-69, pp. 490-506, 2018.

[6] X. Wang and R. A. Khalil, "Matrix metalloproteinases, vascular remodeling, and vascular disease," Advances in Pharmacology, vol. 81, pp. 241-330, 2018.

[7] F. G. Spinale and N. M. Wilbur, "Matrix metalloproteinase therapy in heart failure," Current Treatment Options in Cardiovascular Medicine, vol. 11, no. 4, pp. 339-346, 2009.

[8] A. Yabluchanskiy, Y. Li, R. J. Chilton, and M. L. Lindsey, "Matrix metalloproteinases: drug targets for myocardial infarction," Current Drug Targets, vol. 14, no. 3, pp. 276-286, 2013.

[9] G. Meng, J. Liu, S. Liu et al., "Hydrogen sulfide pretreatment improves mitochondrial function in myocardial hypertrophy via a SIRT3-dependent manner," British Journal of Pharmacology, vol. 175, no. 8, pp. 1126-1145, 2018.

[10] G. Meng, S. Zhao, L. Xie, Y. Han, and Y. Ji, "Protein S-sulfhydration by hydrogen sulfide in cardiovascular system," British Journal of Pharmacology, vol. 175, no. 8, pp. 1146-1156, 2018.

[11] I. A. Sobenin, V. A. Myasoedova, M. I. Iltchuk, D. W. Zhang, and A. N. Orekhov, "Therapeutic effects of garlic in cardiovascular atherosclerotic disease," Chinese Journal of Natural Medicines, vol. 17, no. 10, pp. 721-728, 2019.

[12] R. Padiya, D. Chowdhury, R. Borkar, R. Srinivas, M. Pal Bhadra, and S. K. Banerjee, "Garlic attenuates cardiac oxidative stress via activation of PI3K/AKT/Nrf2-Keap1 pathway in fructose-fed diabetic rat," PLoS One, vol. 9, no. 5, 2014.

[13] G. Kaur, R. Padiya, R. Adela et al., "Garlic and resveratrol attenuate diabetic complications, loss of $\beta$-Cells, pancreatic and hepatic oxidative stress in streptozotocin-induced diabetic rats," Frontiers in Pharmacology, vol. 7, 2016.

[14] M. R. Sultana, P. K. Bagul, P. B. Katare, S. Anwar Mohammed, R. Padiya, and S. K. Banerjee, "Garlic activates SIRT-3 to prevent cardiac oxidative stress and mitochondrial dysfunction in diabetes," Life Sciences, vol. 164, pp. 42-51, 2016.

[15] T. N. Khatua, R. M. Borkar, S. A. Mohammed, A. K. Dinda, R. Srinivas, and S. K. Banerjee, "Novel sulfur metabolites of garlic attenuate cardiac hypertrophy and remodeling through induction of $\mathrm{Na}(+) / \mathrm{K}(+)$-ATPase expression," Frontiers in Pharmacology, vol. 8, 2017.

[16] L. Scheffler, Y. Sauermann, A. Heinlein, C. Sharapa, and A. Buettner, "Detection of volatile metabolites derived from garlic (Allium sativum) in human urine," Metabolites, vol. 6, no. 4 , p. $43,2016$.

[17] L. Scheffler, Y. Sauermann, G. Zeh et al., "Detection of volatile metabolites of garlic in human breast milk," Metabolites, vol. 6, no. 2, p. 18, 2016.

[18] E. K. Lee, S. W. Chung, J. Y. Kim et al., “Allylmethylsulfide Down-Regulates X-Ray Irradiation-Induced Nuclear Factor$\kappa \mathrm{B}$ Signaling in C57/BL6 Mouse Kidney," Journal of Medicinal Food, vol. 12, no. 3, pp. 542-551, 2009.
[19] L. D. Lawson and Z. J. Wang, "Allicin and allicin-derived garlic compounds increase breath acetone through allyl methyl sulfide: use in measuring allicin bioavailability," Journal of Agricultural and Food Chemistry, vol. 53, no. 6, pp. 19741983, 2005.

[20] L. Lawson and S. Hunsaker, "Allicin bioavailability and bioequivalence from garlic supplements and garlic foods," Nutrients, vol. 10, no. 7, p. 812, 2018.

[21] J. D'Ambrosi and N. Amin, "Hyperinflation of isoproterenol," Journal of Pharmacy Practice, vol. 31, no. 4, pp. 390-394, 2018.

[22] A. I. Othman, M. M. Elkomy, M. A. el-Missiry, and M. Dardor, "Epigallocatechin-3-gallate prevents cardiac apoptosis by modulating the intrinsic apoptotic pathway in isoproterenolinduced myocardial infarction," European Journal of Pharmacology, vol. 794, pp. 27-36, 2017.

[23] Y. Zhang, M. Huo, J. Zhou, and S. Xie, "PKSolver: an add-in program for pharmacokinetic and pharmacodynamic data analysis in Microsoft Excel," Computer Methods and Programs in Biomedicine, vol. 99, no. 3, pp. 306-314, 2010.

[24] H. Ohkawa, N. Ohishi, and K. Yagi, "Assay for lipid peroxides in animal tissues by thiobarbituric acid reaction," Analytical Biochemistry, vol. 95, no. 2, pp. 351-358, 1979.

[25] G. L. Ellman, "Tissue sulfhydryl groups," Archives of Biochemistry and Biophysics, vol. 82, no. 1, pp. 70-77, 1959.

[26] H. Aebi, Catalase A2, in methods of enzymatic analysis, Academic Press, Second edition, 1974.

[27] W. J. Shen, C. Y. Hsieh, C. L. Chen et al., "A modified fixed staining method for the simultaneous measurement of reactive oxygen species and oxidative responses," Biochemical and Biophysical Research Communications, vol. 430, no. 1, pp. 442-447, 2013.

[28] R. Hegarty and A. Dhawan, "Fifteen-minute consultation: the child with an incidental finding of elevated aminotransferases," Archives of disease in childhood - Education \& practice edition, vol. 103, no. 5, pp. 228-230, 2018.

[29] Y. Saidu, M. J. Usman, S. A. Isa et al., "Biochemical and histological changes in the heart of post-partum rats exposed to Natron," Indian Heart Journal, vol. 70, no. 6, pp. 887-893, 2018.

[30] S. A. Bageghni, K. E. Hemmings, N. Zava et al., "Cardiac fibroblast-specific p38 $\alpha$ MAP kinase promotes cardiac hypertrophyviaa putative paracrine interleukin-6 signaling mechanism," The FASEB Journal, vol. 32, no. 9, pp. 4941-4954, 2018.

[31] S. Panda, A. Kar, and S. Biswas, "Preventive effect of Agnucastoside C against isoproterenol-induced myocardial injury," Scientific Reports, vol. 7, no. 1, p. 16146, 2017.

[32] T. Zhou, E. Prather, D. Garrison, and L. Zuo, "Interplay between ROS and antioxidants during ischemia-reperfusion injuries in cardiac and skeletal muscle," International Journal of Molecular Sciences, vol. 19, no. 2, p. 417, 2018.

[33] K. Huynh, B. C. Bernardo, J. McMullen, and R. H. Ritchie, "Diabetic cardiomyopathy: mechanisms and new treatment strategies targeting antioxidant signaling pathways," Pharmacology \& Therapeutics, vol. 142, no. 3, pp. 375-415, 2014.

[34] J. Farías, V. Molina, R. Carrasco et al., "Antioxidant therapeutic strategies for cardiovascular conditions associated with oxidative stress," Nutrients, vol. 9, no. 9, p. 966, 2017.

[35] S. Hinderer and K. Schenke-Layland, "Cardiac fibrosis - A short review of causes and therapeutic strategies," Advanced Drug Delivery Reviews, vol. 146, pp. 77-82, 2019. 
[36] N. Cui, M. Hu, and R. A. Khalil, "Biochemical and biological attributes of matrix metalloproteinases," Progress in Molecular Biology and Translational Science, vol. 147, pp. 1-73, 2017.

[37] J. Radosinska, M. Barancik, and N. Vrbjar, "Heart failure and role of circulating MMP-2 and MMP-9," Panminerva Medica, vol. 59, no. 3, pp. 241-253, 2017.

[38] H. Tian, M. Cimini, P. W. M. Fedak et al., "TIMP-3 deficiency accelerates cardiac remodeling after myocardial infarction," Journal of Molecular and Cellular Cardiology, vol. 43, no. 6, pp. 733-743, 2007.

[39] W. Yao, N. Wang, J. Qian et al., "Renal sympathetic denervation improves myocardial apoptosis in rats with isoproterenol-induced heart failure by downregulation of tumor necrosis factor- $\alpha$ and nuclear factor- $\kappa \mathrm{B}$," Experimental and Therapeutic Medicine, vol. 14, no. 5, pp. 4104-4110, 2017.

[40] B. Ouyang, Z. Li, X. Ji, J. Huang, H. Zhang, and C. Jiang, "The protective role of lutein on isoproterenol-induced cardiac failure rat model through improving cardiac morphology, antioxidant status via positively regulating $\mathrm{Nrf} 2 / \mathrm{HO}-1$ signalling pathway," Pharmaceutical Biology, vol. 57, no. 1, pp. 529-535, 2019.

[41] B. Yang, D. Ye, and Y. Wang, "Caspase-3 as a therapeutic target for heart failure," Expert Opinion on Therapeutic Targets, vol. 17, no. 3, pp. 255-263, 2013.

[42] S. Kamada, U. Kikkawa, Y. Tsujimoto, and T. Hunter, "Nuclear translocation of caspase-3 is dependent on its proteolytic activation and recognition of a substrate-like protein(s)," The Journal of Biological Chemistry, vol. 280, no. 2, pp. 857860, 2005. 